\title{
Stakeholder Analysis: Process Modell
}

\author{
CELAR, S.; TURIC, M. \& VICKOVIC, L.
}

Abstract: Stakeholder analysis receives little attention in software development literature. In the article we propose a process model for the stakeholder analysis method as a permanent process. Stakeholder analysis begins in the early project stage and lasts during the whole project. We propose a method for clearly presentation of four stakeholder characteristics in only one two-dimensional diagram. The process model and presentation method are used for analysis of 28 internal stakeholders in PIVIS project. Stakeholder register structure is also given in the article.

Key words: stakeholder management strategy, four-dimensional stakeholder analysis (4DSA), Enterprise Resource Planning (ERP), software engineering
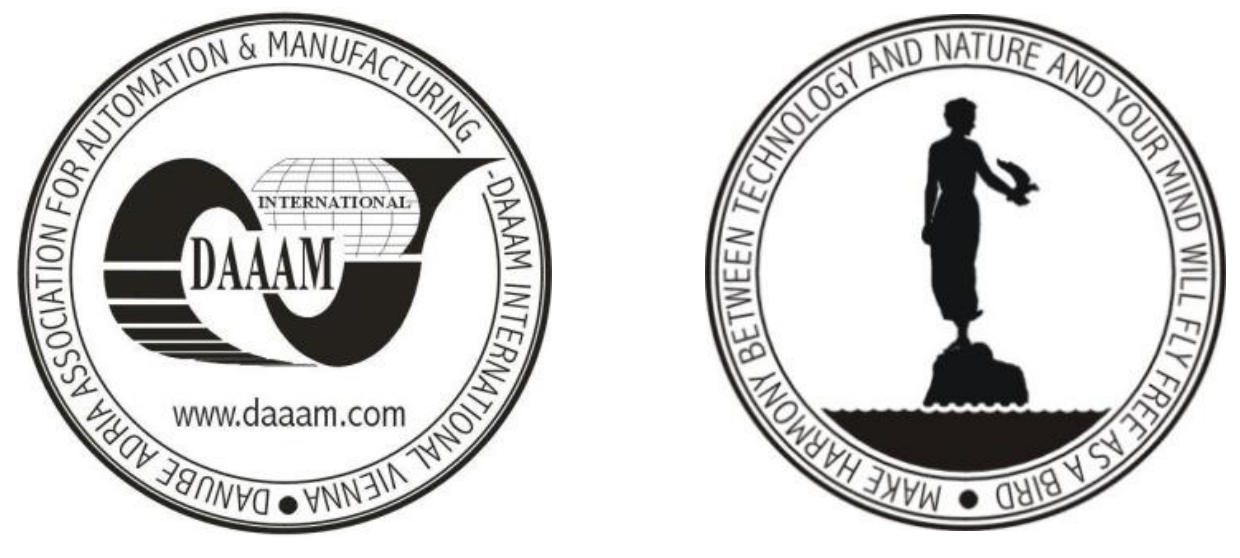

Authors' data: Prof. Celar S[tipe]; mag.ing.comp. Turic, M[ili]; Dr. Vickovic, L[inda], University of Split, Faculty of Electrical Engineering, Mechanical Engineering and Naval Architecture, R. Boskovica 32, 21000 Split, Croatia, stipe.celar@fesb.hr, mili.turic@gmail.com, linda.vickovic@cern.hr

This Publication has to be referred as: Celar S[tipe]; Turic M[ili]; Vickovic, L[inda] (2010). Stakeholder Analysis: Process Modell, Chapter 43 in DAAAM International Scientific Book 2010, pp. 489-496, B. Katalinic (Ed.), Published by DAAAM International, ISBN 978-3-901509-74-2, ISSN 1726-9687, Vienna, Austria DOI: $10.2507 /$ daaam.scibook.2010.43 


\section{Introduction}

Stakeholders in software projects are persons or organizations who are actively involved in the project or whose interests may be positively or negatively affected by the performance or completion of the project (PMI, 2008). Stakeholders may also have a significant influence over the project, its deliverables, and the project team members.

Each software project may have different types of stakeholders (PMI, 2008), (Sommerville, 2007), (Pressman, 2001). Their roles in project and their primary concerns around these projects differ substantially (s. Fig. 1). Evaluating their characteristics and managing their interrelationship appropriately have a strong impact on the project success. That management approach depends on organisation's management culture and readiness. Large software development projects are sensitive to such stakeholder influences because even small deviations in the beginning can cause problems in later project phases. To avoid this it is necessary to have a clear model for stakeholder analysis during the whole project.

In this paper we propose a stakeholder analysis (SA) model applied on Enterprise Resource Planning (ERP) development project PIVIS. The main contributions of this paper are: (i) defining SA in an holistic way, during the hole project, (ii) proposing process model for SA and, (iii) proposing graphical presentation of four stakeholder characteristics on only one two-dimensional diagram. The rest of this paper is organized as follows: Section II presents the SA literature. In Section III we present process model of SA. In Section IV we present the SA case based on 28 stakeholders in PIVIS project and describe the presentation method. Section V presents our conclusions and describes the future work.

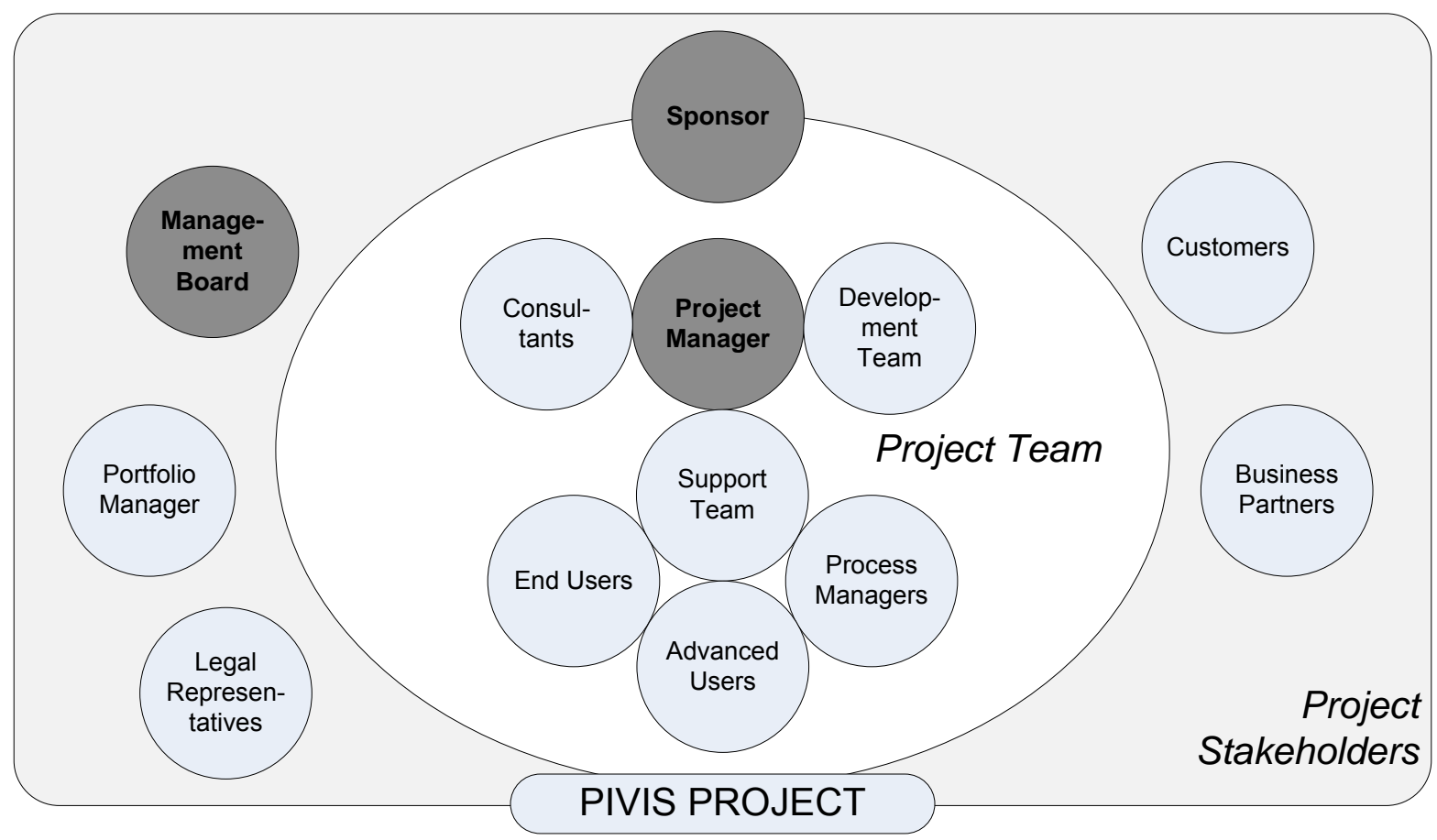

Fig. 1. The relationship between PIVIS project and stakeholders 


\section{Stakeholder analysis in software development - literature overview}

Traditional software engineering literature mostly agrees in naming the key stakeholders as end-users, customers, sponsors, managers, team members, suppliers, domain experts or the public (IEEE, 2004), (Sommerville, 2007), (Williams et al., 2010). The stakeholders are included in the project from the Requirements Engineering (RE) phase (IEEE, 2004), (Sommerville, 2007). The key term concerning stakeholders is 'stakeholder identification' or 'stakeholder identification process' (SIP). They mostly agree about SIP's benefits (Pacheco \& Tovar, 2007): a proper selection of stakeholders improves the coverage of requirements, avoids overlapping of requirements in the user community, and allows for a more rational organization of project requirements. A prerequisite for this is that all the stakeholders are identified, the nature of their 'stake' analyzed, and their requirements elicited (IEEE, 2004). In the software engineering and ERP literature SA receives little attention (Pacheco \& Tovar, 2007), (Bancroft et al., 1998), (IEEE, 2004).

From the management point of view, it is critical for project success to identify the stakeholders early in the project (PMI, 2008), (Smith, 2000) and to identify their roles, cooperativeness, specific knowledge and similar characteristics. Once such activities are made then overall stakeholder's influence on a project and stakeholder analyses with corresponding stakeholder management strategy can be developed. In PMBOK (PMI, 2008) SA is treated as tool\&technique in Stakeholder Identifing process.

\section{Process model for stakeholder analysis}

Stakeholder analysis in the early project phase may not include all stakeholders or provide enough information about all their characteristics, but it should provide initial data for other project documents (like teams forming, risk analyses, project plan or communication plan). This is especially important in large projects because small failures in the early phases can have large implications on project success. In fact, large software project usually includes huge number of stakeholders and it is necessary to identify all relevant stakeholders and their roles in early project phase, in order to be able to make good requirements and expectation elicitation. Completeness, correctness and consistency in the Software Requirement Specification Quality (SRSQ) can be significantly ensured by applying proper SA (IEEE, 1998).

During the project, SA is updated with additional information (like new stakeholders, or new knowledge about old ones). For example, stakeholder register on large project could be long, and missing to identify or even wrongly evaluate some stakeholders, could lead to incomplete, incorrect or inconsistent SRSQ. That means that SA could be described as a set of activities performed during the whole project. In the literature SA is described rather as an activity then as a process. In fact, SA consists of activities that can be organized into several (sub) processes (simultaneous or consecutive), with their inputs and outputs. 
Software Requirement Specification is important but not the only reason to perform stakeholder identification activities described in existing initiatives in software development (for example, SWEBOK, IEEE Standard 830). Other project tasks (for example, training, system integration) can also include new stakeholders, and therefore require SA. Seen from the project life cycle point of view, SA may be necessary to make in the early phase of the project but in any later stage. Such and similar stakeholder changes can significantly affect the project objectives. It is therefore necessary to make appropriate methodology for the management of relevant changes in stakeholders' characteristics. Model that we propose for SA is presented in Fig. 2.
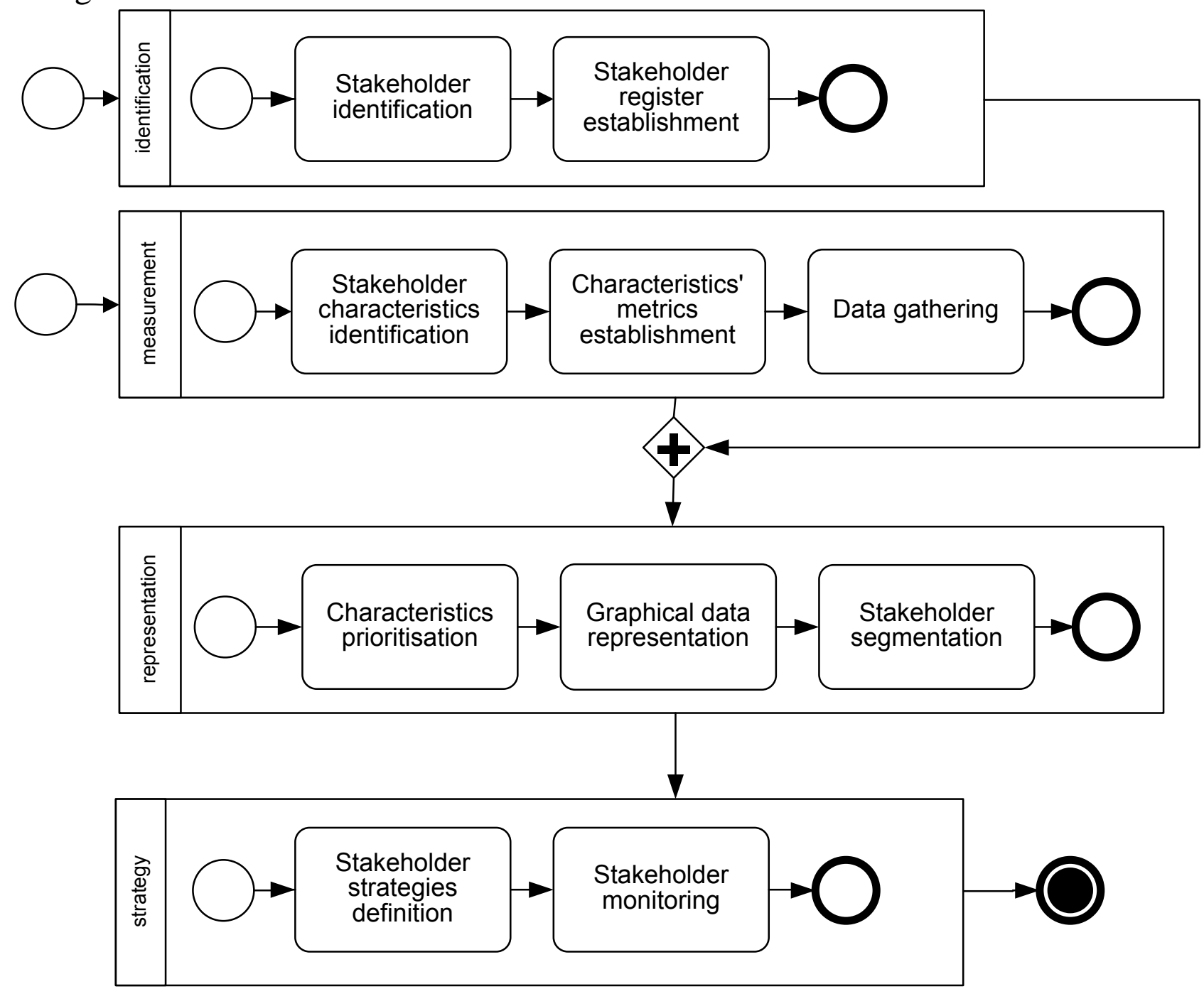

Fig. 2. Stakeholder analysis process

Activities in this model are organized through ten sub processes (from initial stakeholder identification to continuous monitoring). Some of them appear just once (like register establishment) while others are repetitive (it means: they appear several times during the project) (like stakeholder identification, characteristics identification, data gathering, etc.) or permanent process (stakeholder monitoring). Prerequisites for this permanent process should be designed and organized wisely in 
order to manage monitoring effectively. In this way SA and stakeholder monitoring as its sub process contribute to the project success.

\section{Stakeholder analysis for PIVIS project}

Stakeholders of ERP project PIVIS are assessed in terms of four important characteristics:

Power objective power, official or unofficial (from 1 to 5)

Impact personal attitude against project, positive or negative impact on a project (from -5 to 5 )

Knowledge overall knowledge needed in a project and special knowledge about business system useful for the project (from 1 to 5)

Willingness cooperativeness with the project team (from 1 to 5).

These characteristics describe their interest, influence and involvement in the project (PMI, 2008). In order to create effective stakeholder management strategy it is needed to take into account the above characteristics of all stakeholders:

$$
\text { Strategy }=f(\text { Power, Impact, Knowledge, Willingness })
$$

The structure of the stakeholder register in PIVIS project, with four the most important stakeholder characteristics and gathered data is presented in Tab. 1. It is possible to observe a more interesting combination of two characteristics displayed in four quadrants (PMI, 2008), (Williams et al., 2010). According to the equation (1), in this case would be necessary to have six two-variable diagrams (six combinations) for the stakeholder strategy definition.

\begin{tabular}{|c|c|c|c|c|}
\hline Stakeholder ID & Power & Impact & Knowledge & Willingness \\
\hline 1 & 5 & 1 & 1 & 2 \\
\hline 2 & 5 & 1 & 1 & 2 \\
\hline 3 & 5 & 1 & 1 & 2 \\
\hline 4 & 5 & 4 & 4 & 4 \\
\hline 5 & 5 & 4 & 4 & 4 \\
\hline 6 & 4 & 3 & 3 & 4 \\
\hline 7 & 4 & 3 & 5 & 3 \\
\hline 8 & 3 & 2 & 3 & 3 \\
\hline 9 & 4 & 4 & 5 & 4 \\
\hline 10 & 4 & 4 & 5 & 4 \\
\hline 11 & 4 & 4 & 5 & 3 \\
\hline 12 & 3 & 3 & 4 & 2 \\
\hline 13 & 1 & 3 & 2 & 3 \\
\hline 14 & 2 & 2 & 3 & 3 \\
\hline 15 & 2 & 1 & 2 & 3 \\
\hline 16 & 3 & 1 & 1 & 2 \\
\hline 17 & 1 & 1 & 3 & 3 \\
\hline 18 & 2 & 1 & 1 & 2 \\
\hline
\end{tabular}




\begin{tabular}{|c|c|c|c|c|}
\hline Stakeholder ID & Power & Impact & Knowledge & Willingness \\
\hline 19 & 3 & 1 & 2 & 3 \\
\hline 20 & 2 & 1 & 2 & 2 \\
\hline 21 & 3 & 2 & 3 & 2 \\
\hline 22 & 2 & 2 & 3 & 3 \\
\hline 23 & 3 & 2 & 2 & 2 \\
\hline 24 & 1 & 1 & 1 & 3 \\
\hline 25 & 3 & 2 & 4 & 4 \\
\hline 26 & 3 & 2 & 3 & 4 \\
\hline 27 & 4 & 2 & 5 & 5 \\
\hline 28 & 2 & -4 & 2 & 2 \\
\hline
\end{tabular}

Tab. 1. SA of internal stakeholders in PIVIS project (excluding development team)

In order to facilitate results presentation and their later monitoring we have put all four characteristics in one diagram (Fig. 3). The most influential characteristics (power and impact) are the on the main axes (x and $\mathrm{y}$ ). The third characteristic (knowledge) is presented by the size of the circle. In this way, three dimensions are incorporated, but still the forth one is required to present and monitor stakeholder characteristics easily. Further we have applied a new characteristic (willingness) as a fourth variable in the diagram. It is presented as follows: cells that derive from discrete values of $\mathrm{x}$ and $\mathrm{y}$ axes when they are divided into five horizontal columns. Left side indicates little willingness, while the right side indicates a high willingness. It produced several areas for 4-dimensional stakeholder analysis. People placed more on the right side of $\mathrm{x}$ axis are influential ones. Besides positive influences are presented on the positive part of y-axis, while negative influence are on the negative part. The degree of knowledge and interest are nuances that will ultimately determine which management strategy should be applied to particular group.

Once when all characteristics (i.e. variables) are elaborated then gathered data can be processed and presented in the diagram. The SA for 28 stakeholders from the Table 1. is presented in Fig. 3. Some different groups are identified. The labile group of three stakeholders (ID: 1, 2 and 3) is important, because they are influential and on the edge of positive impact, little knowledge and willingness. The next group (ID: 6, $7,9,10,11$ and 27) has a highly positive impact. In addition, stakeholders from this group are very cooperative and have high domain knowledge - these are the key users. Close to this group are two important team members (ID: 4 and 5) with very high power and slightly smaller domain knowledge - they are also important team members with special treatment. On the other hand there is a single person (ID: 28) with a highly negative impact, but fortunately negligible other characteristics. Appropriate strategy was defined for each stakeholder group. 


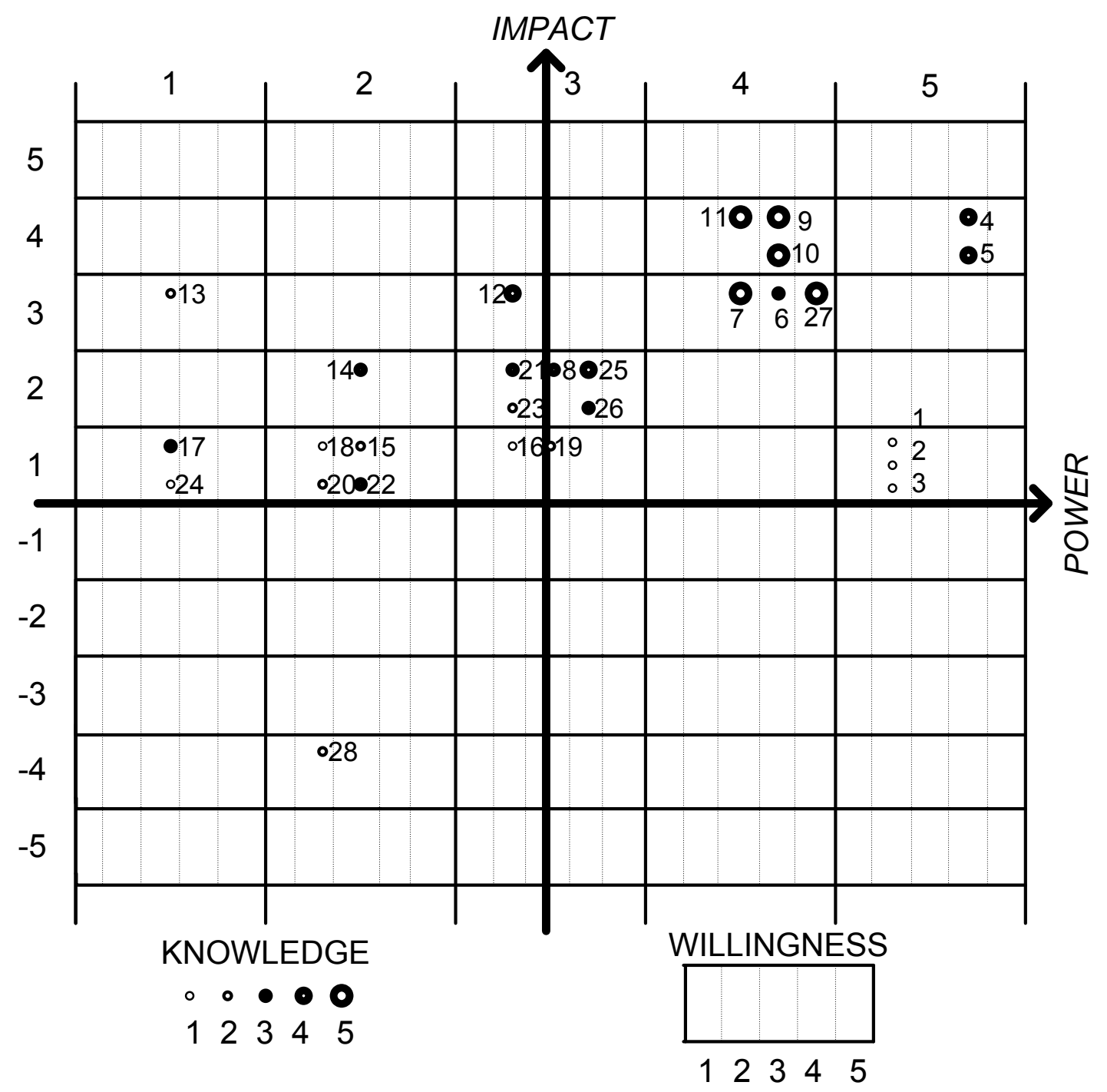

Fig. 3. 4D stakeholder analysis (4DSA) for PIVIS ERP project

\section{Conclusions and future work}

This article gives a detailed description of process model of stakeholder analysis. According to the process model, stakeholder analysis is important process and should be should be treated holistically, from the early stage of the project by the end of the project. The second novelty presented by this article is the method for a presentation of four variables in only one two-dimensional diagram.

An example of applying the process model to the analysis of internal stakeholders in the software development project and presentation method is given in the article.

It is important to note that this process model can be applied for stakeholder analysis to all types of projects. The 4-variable presentation method, called fourdimensional stakeholder analysis (4DSA) (Celar et al., 2010), used for a presentation of stakeholder characteristics can generally be used as a presentation method.

Future research will be directed to the finding appropriate metric and model for measuring the productivity of small software team. 


\section{References}

Bancroft, N.H.; Sep, H. \& Sprengel, A. (1998). Implementing Sap R/3 : How To Introduce a Large System into a Large Organization, 2nd Edition, Manning Publications Co., ISBN 013889213X, Greenwich

Celar, S.; Turic, M. \& Vickovic, L. (2010). 4DSA: 4-Dimensional Presentation of Stakeholder Analysis in Large Software Project (2010). 0003-0005, Annals of DAAAM for 2010 \& Proceedings of the 21 st International DAAAM Symposium, ISBN 978-3-901509-73-5, ISSN 1726-9679, pp 0002, Editor B. Katalinic, Published by DAAAM International,Vienna, Austria 2010

IEEE (2004). Guide to the Software Engineering Body of Knowledge. New York, Available from: http://www.swebok.org, Accessed on: 2010-08-13

IEEE (1998). Guide to Software Requirements Specification, IEEE Std. 830-1998. IEEE Press. Piscataway, NJ

Pacheco, C. \& Tovar, E. (2007). Stakeholder Identification as an Issue in the Improvement of Software Requirements Quality, CAiSE 2007, J. Krogstie, A.L.

Opdahl, and G. Sindre (Eds.), pp. 370-380, 2007, Springer-Verlag, Berlin Heidelberg

PMI (2008). A Guide to the Project Management Body of Knowledge (PMBOK® Guide), Fourth edition, Project Management Institute, ANSI/PMI 99-001-2008

Pressman, R. (2001). Software engineering: a practitioner's approach, 5th ed, McGraw-Hill, ISBN 0073655783, New York, USA, 2001.

Smith, L.W. (2000). Project clarity through stakeholders analysis. The Journal of Defense Software Engineering. Issue December 2000, Available from: http://stsc.hill.af.mil/crosstalk/2000/12/smith.html, Accessed on: 2010-08-13

Sommerville, I. (2007). Software Engineering, 8th ed., Pearson Education Limited, ISBN: 978-0-321-31379-9, London

Williams, C.; Wagstrom, P.; Ehrlich, K.; Gabriel, D.; Klinger, T.; Martino, J. \& Tarr, P. (2010). Supporting Enterprise Stakeholders in Software Projects, CHASE 2010, pp. 109-112, May 2, 2010, Cape Town, South Africa 